Tohoku J. exp. Med., 1981, 134, 221-222

Short Report

\title{
Serum $\beta_{2}$-Microglobulin in Ghronic Liver Diseases
}

\author{
Shozo Nakamura, Yoshiaki Takezawa* and Toshiyuki \\ MaEda $\dagger$ \\ Tohoku University Health Center, Sendai 980, *the First \\ Department of Internal Medicine, Tohoku University School \\ of Medicine, Sendai 980, and †Hikarigaoka Spellman \\ Hospital, Sendai 983
}

\begin{abstract}
Nakamura, S., Takezawa, Y. and Maeda, T. Serum $\beta_{2}$-Microglobulin in Chronic Liver Diseases. Tohoku J. exp. Med., 1981, 134 (2), 221-222 Serum $\beta_{2}$-microglobulin was determined in 53 patients with chronic liver diseases. No elevation was shown in fatty liver due to obesity or alcoholism. Serum $\beta_{2^{-}}$ microglobulin was abnormal only in $4 \%$ of the patients with chronic hepatitis. Determination of serum $\beta_{z}$-microglobulin seems not useful for the differential diagnosis between chronic hepatitis and fatty liver due to obesity or alcoholism. Serum $\beta_{2}$-microglobulin was elevated in $29 \%$ of the patients with alcoholic liver cirrhosis, in $41 \%$ of those with non-alcoholic liver cirrhosis, and in $75 \%$ of those with primary liver carcinoma. The average serum $\beta_{2}$-microglobulin concentration was significantly higher in non-alcoholic liver cirrhosis than in alcoholic liver cirrhosis. There was a significant correlation between serum $\beta_{2}$-microglobulin and $\gamma$-globulin concentrations in liver cirrhosis. $-\beta_{2}$-microglobulin; fatty liver due to obesity; chronic hepatitis; liver cirrhosis; $\gamma$-globulin
\end{abstract}

Serum $\beta_{2}$-microglobulin has been hitherto determined mainly in renal diseases and in malignant tumors. Recently Hällgren (1979) reported that serum $\beta_{2}$-microglobulin was elevated in most patients with chronic (active or persistent) hepatitis or alcoholic liver cirrhosis but was mostly within the normal range in patients with alcoholic fatty liver. As we previously showed (Nakamura et al. 1980), glutamic pyruvic transaminase, glutamic oxalacetic transaminase, and $\gamma$-glutamyl transpeptidase are occasionally elevated in obese subjects, and this presents a difficult problem of differentiation from chronic hepatitis. Hence we measured serum $\beta_{2}$-microglobulin in chronic liver diseases in order to determine its usefulness in the differentiation, especially, between fatty liver due to obesity and chronic hepatitis.

Serum $\beta_{2}$-microglobulin was measured in 24 controls and in 53 patients with chronic liver diseases in the First Department of Internal Medicine of Tohoku University Hospital and in the referred hospitals by radioimmunoassay using Phadebas $\beta_{2}$-micro test (Pharmacia AB, Uppsala, Sweden). Patients with elevated serum creatinine concentrations (more than $1.2 \mathrm{mg} / 100 \mathrm{ml}$ ) were excluded from the study. Values over mean plus 3 times standard deviations of the controls $(2.4 \mathrm{mg} / 1)$ were thought to be abnormal. Comparisons of frequency of abnormal values were analyzed with Fischer's direct calculation method of probability, and those of average concentrations with Student's $t$-test.

The results are shown in Fig. 1. No elevation was found in fatty liver due to obesity or alcoholism. In chronic hepatitis, though the average $\beta_{2}$-microglobulin concentration was significantly higher than the controls $(p<0.05)$, the incidence of abnormal values was only $4 \%$, and was not significantly different from that in the controls or in fatty liver due

Received for publication, March 11, 1981. 


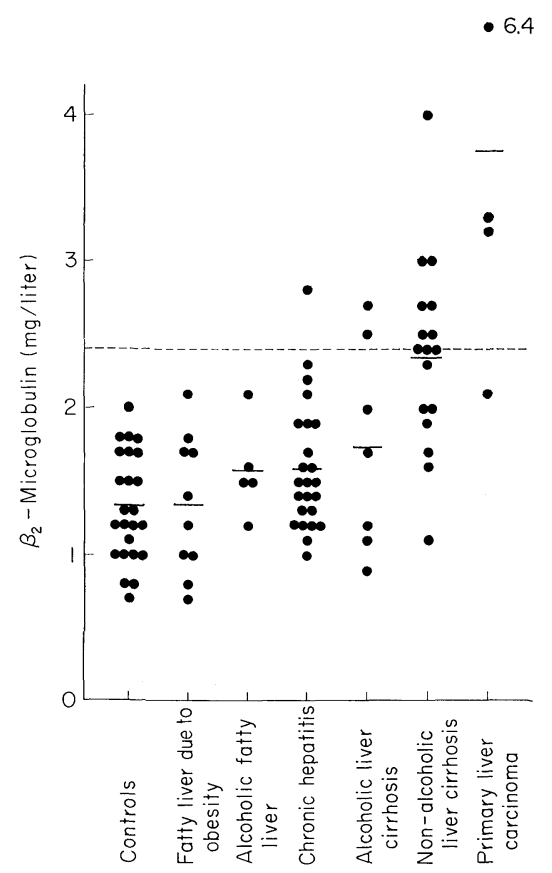

Fig. 1. Serum $\beta_{2}$-microglobulin concentrations in chronic liver diseases. The dotted line indicates the normal upper limit.

to obesity or alcoholism. Determination of serum $\beta_{2}$-microgloublin seems to be not useful for the differential diagnosis between chronic hepatitis and fatty liver due to obesity or alcoholism. There was no significant difference in the serum $\beta_{2}$-microglobulin level between 6 cases of chronic hepatitis with more than 200 Karmen units of glutamic pyruvic transaminase and 18 cases with less than 200 Karmen units, or between 4 cases of chronic active hepatitis and 20 cases of chronic persistent hepatitis.

The incidences of elevated values in alcoholic liver cirrhosis, non-alcoholic liver cirrhosis, and primary liver carcinoma were $29 \%, 41 \%$, and $75 \%$, respectively, and were significantly higher than that in the controls $(p=0.045,0.0009$, and 0.001 , respectively). The average serum $\beta_{2}$-microglobulin concentration was significantly higher in nonalcoholic cirrhosis $(2.37 \mathrm{mg} / 1)$ than in alcoholic cirrhosis $(1.73 \mathrm{mg} / 1)(p<0.05)$. There was a statistically significant correlation between serum $\beta_{2}$-microglobulin and $\gamma$-globulin concentrations in liver cirrhosis $(r=0.46 ; p<0.05)$. It is interesting for understanding of mechanism of elevation in serum $\beta_{2}$-microglobulin concentrations in liver diseases that there are a significant difference between alcoholic and non-alcoholic cirrhosis and also a significant correlation between $\beta_{2}$-microgloublin and $\gamma$-globulin concentrations in liver cirrhosis.

\section{References}

1) Hällgren, R. (1979) Serum $\beta_{2}$-microglobulin in liver disease. Scand. J. clin. Lab. Invest., 39, 441-447.

2) Nakamura, S., Takezawa, Y., Nakajima, Y. \& Maeda, T. (1980) Elevation of glutamic pyruvic transaminase and $\gamma$-glutamyl transpeptidase in obesity. Tohoku J. exp. Med., 132, 473-478. 